\title{
MANAGEMENT OF INN FRONT OFFICE
}

\section{BIBHUTI B PRADHAN}

Research Scholar, Department of Management, Siksha 'O' Anusandhan (Deemed to be University),

Bhubaneswar, Odisha, India

\begin{abstract}
This examination reviewed dwelling deficiencies on help with an accentuation on the front office. While there are different assessments uncovering high delegate turnover in the neighborliness business few have broken down issues that add to these turnover or progressively broad related deficiencies on help. To address this gap, this assessment coordinated semi-sorted out gatherings with front office directors from hotels with various degrees of organization in India. Results separated different deficiently examined issues that add to staff turnover. The disclosures exhibit that housing staff turnover and the repercussions for motel execution are a result of a flighty game plan of causal components. Results may be used by housing bosses in watching out for their deficiencies on help and improving execution. The Front office in general is by all accounts one region which is a key advertiser of the visitor fulfillment. The inspirational systems utilized for the staff like the Star-o-meter, Representative of the Month Grant, showing such data on the presentation sheets for everybody to know are viable persuasive instruments. It can likewise be said that the preparation rehearses just as the enrollment strategies for the lodging are successful.
\end{abstract}

KEYWORDS: Causal Variables, Front Office, Human Asset Management and Lodging Turnover

Received: Jun 08, 2020; Accepted: Jun 28, 2020; Published: Aug 27, 2020; Paper Id.: IJMPERDJUN2020909

\section{INTRODUCTION}

The essentialness of human resource the administrators for organization quality, customer devotion and reliability, high ground and legitimate execution is included in various speculations, models and observational investigations[1]. Human resource the official's approaches and practices genuinely sway specialist data, aptitudes, limits, and outlook and direct which are critical for firm unequivocal piece of leeway. Human resource rehearses, for instance, planning and calling improvement attempt to convince, satisfy and hold agents and in this manner to achieve satisfied and immovable customers. Managing laborers feasibly is the best test looked by housing director[2].

The trial of regulating HR has been commonly discussed in the neighborliness the official's writing especially focusing on specialist turnover and staff deficiencies. Likewise, a variety of other human related issues may be recognized, for instance, inconvenience of pulling in and holding staff, managing a contrasting workforce, low differentiation and status of friendliness occupations, developing people and injury of increasingly prepared experts, the need to get ready delegates in new correspondence and information progresses, HIV/Helps issues, business law, least wages and restrictive government strategies. This assessment hopes to break down the essentialness and effect of these issues on staff turnover and motel management feasibility in India[3].

While there is a gathering of writing identifying with deficiencies on help in the kind disposition business in various countries considers in India are restricted. Past India's assessments have focused on turnover objective and are 
quantitative in nature and various housing shortages on help have been disregarded. Explicitly scarcely any examinations have focused on the Front Office Department[4]. This examination is the first to use an inductive and abstract approach to manage see deficiencies on help looked by front office directors in India and the plans they are embracing. It fixates on front work zone delegates because free of motel types and sizes, this division is the rule contact point for guests and gives guests' initial presentation of an inn. The accomplishment of a hotel by and large depends upon front office staff organization transport and assurance that agents are capable in particular, correspondence, social and language aptitudes[5].

\subsection{Shortages on Help Happened in Friendliness Business:}

The importance of deficiencies on help in the cordiality business is driven by the high dependence of motel execution on its workers. Accurate ponders exhibit a wide combination of approaches to manage the organization of HR influenced by the fundamental response to the possibility of the internal and external condition. Associations may grasp methods of advancement, quality improvement or cost decline. Advancement and quality update are procedures requiring a long stretch perspective and incorporate improving the idea of things and administrations. A cost decline method incorporates making things and organizations at the most insignificant cost. While the long stretch perspective requires high enthusiasm for HR, a cost decline approach to manage warmth organizations decreases enthusiasm for HR and results in various dangerous deficiencies on help[6].

The human resource writing proposes hotels hoping to lead their opponents and become known for their quality help should be specific in staffing, provide guidance and getting ready, offer forceful and sensible remuneration and benefits, and incorporate and connect with agents. These practices require high theory and may be angry with specialist turnover and solicitation consistency. An occupation in the housing industry is consistently worked by moving beginning with one affiliation then onto the following and this preparation is typical in tremendous and sumptuous motels.

Additionally, demand in the cordiality business shifts and remembering that having too barely any specialists may cripple organization quality, having an exorbitant number of never-ending (full-time) agents is a risk since work cost is the greatest working use. High laborer turnover and fluctuating solicitation has driven hotel directors to get a cost decline methodology by practicing offhand staffing, giving immaterial and hands on setting up, no expert achievement openings, limited business security and below average compensation. This results in different staff related issues for motel boss to oversee.

\subsection{Answers for Issues:}

A study of the friendliness composing shows shortages on help can be amassed around issues of high delegate turnover, inconvenience in attracting and holding capable workers, staff insufficiencies, and poor train and occupation duty. Among these issues, laborer turnover appears, apparently, to be the most testing. Specialist turnover is described as the deliberate or programmed ceaseless withdrawal of a staff part from an affiliation. Laborer turnover is a critical issue in the motel business, especially in made countries, for instance, the Assembled Realm and Australia. Extraordinary turnover including significant staff people upsets and demolishes the reasonability of an affiliation. Reducing turnover is critical in light of the fact that it lessens selection, decision and getting ready expenses, and improves the idea of organization passed on.

In India, different examinations have focused on specialist turnover objectives. Indian considers have found that respondents with high mean to leave are: the people who need transient business, were affected by others to search for work in the business, and are increasingly organized towards peer bundle partnership instead of the specific work. Human resource practices, legitimate citizenship direct and a psychological understanding add to reducing turnover objective. The 
negative association between helping behavior and turnover objective is more grounded among female delegates made sure about that position content (testing, broad and different works) is a vital marker of housing managers' turnover point. They furthermore found that age is a basic variable in unveiling purposes behind plan to leave the affiliation. Progression openings and remuneration are basic pointers of turnover objective for the 18 to 30 age pack people who had as of late started their employment while work-family balance was huge for those in the 30 to 41 age gathering and the more settled age gathering (40 to 51) people will undoubtedly leave a relationship with a course of action of execution related pay.

Other ask about in India has reviewed the interest and upkeep of capable and powerful delegates. A low degree of human capital among the workforce has been viewed as a reason for an insufficiency of skilled work need India. In spite of the way that the amount of hotel schools is growing, there is a declining eagerness among warmth understudies and graduates in a calling in the motel business. As the result, dwelling affiliations use outside workers or less skilled optional school graduates who are anxious to take an area level position and work for low wages. Such a situation makes supervising staff for prevalent help transport a troublesome task.

Course and getting ready familiarizes new delegates with the affiliation and fabricates laborers' data, aptitudes and abilities to play out their essential tasks. Getting ready should incorporate a readiness needs assessment, expertly arranged instructional classes, gifted tutors, similarly as planning evaluation and records keeping. Offering forceful and sensible remuneration to agents is furthermore critical for laborer support. Friendliness industry non-regulatory agents have low compensation diverged from various endeavors, provoking high specialist turnover, staff inadequacies and inconvenience in attracting and holding skilled staff. To hold experienced and talented agents, lodgings must outfit appealing compensation with monetary and non-budgetary rewards similarly as affirmation[7].

Various neighborliness firms at any rate don't have sufficient resources for offer engaging and centered compensation. Practicing an intriguing and thoughtful oversight and the official's style can help satisfy and hold delegates by reducing the weight of the working air and making obligation, trust and a prodding working environment. A boss with extraordinary social capacities and similarity with staff people sees, respects and remembers them for essential administration. Affiliations that draw in laborers, consider work upgrade, improve the condition of agent settlement, cause a culture accommodating for legitimate presentation, to assess progressive execution and give a strong organization and vision. This writing overview has perceived different issues or the administrator's practices that impact staff turnover in the housing division. In this investigation study, these practices are breaking down to choose their good judgment and use as answers for deficiencies on help in motels of various level of organization in Indian northern area.

\section{METHODOLOGY}

An emotional research approach and semi-sorted out talk with methodology was used for this examination. Data collection was finished in December 2012 using solace analyzing. Hotel chiefs were enrolled by phone. Fourteen front office bosses from hotels of various degrees of organizations were solely chatted with very close. Overall the gathering on personnel shortages took 50 minutes[8]. Two crucial inquiries were posed: "What are the shortages on help looked by front office administrators?" and "How do boss light up these issues?" The gatherings were recorded, interpreted and analyzed using topical substance examination. Content examination is an investigation methodology for making repeat and genuine inferences from works and empowers an expert to discover what the substance reveals. With topical substance examination, data is bankrupt somewhere near subjects that ascents up out of the data. Each transcript was deliberately and totally scrutinized to recognize the personnel shortages with codes allotted to bits of the substance. Codes concerning 
diverse personnel shortages were accumulated reliant on their similarities into not many reasonable subjects[9].

The individuals were regulatory or administrative delegates of lodgings in India northern region and made sure about an extent of experience, territories, motel types, and hotel divisions. The task of the eleven managerial agents included front office chief, aide front office supervisor, room division director and activity and team lead. For order purposes, a code name was given out to every executive. The code name reflects the director's position, the housing's star rating and the territory of the motel. Three of the executives were from four and five-star, and excess boutique motels. Their association with the motel business went between eight to twelve years. Four boss were from India managing a threestar and a spending hotel. Their contribution with the hotel business went between three to eight years. One director was from a three-star dwelling in north India[10]. He had 18 years work contribution with the hotel business. Another six individuals were from three-star and spending hotels. Their contribution with the hotel business went between two to twenty years.

\section{RESULTS}

Eight subjects were perceived by social event the 20 issues from the outset recognized. The eight subjects and related issues were: staff inadequacy, high specialist turnover, terrible appearing (slow, inefficient, uncivilized and bungles made at work), low-gifted agents (feebleness to use the property the administrators system, poor English capacity and poor correspondence capacity), loathsome character (inconsiderate, horrendous attitude and rowdiness), nonattendance of obligation (delay, truancy, emergency leave, restorative leave and taking long early afternoon breaks), over the top socialization (delegates who partner a ton among themselves with the objective that it conversely impacts their work) and wrong conduct. All of these subjects is analyzed underneath.

\subsection{Staff Deficiency}

Off all the shortages on help, staff lack was referenced the most. According to the front office managers, staff lacks at the front office are realized by the difficulty of getting and holding agents due to the low compensation and long working hours. A four-star dwelling pays as small as indicated by month for front work region staff. Staff insufficiencies make it difficult to pass on splendid customer help.

Two procedures for dealing with the issue of staff inadequacies were inspected. One executive hotels to using part-timekeepers from a near to school while another handles staff inadequacy issue by paying extra time. A boss communicated that paying extra time is his supported plan because accommodating or low upkeep business constructs the pace of specialist turnover and means delegates don't have work understanding. Also, part-tickers are not as skilful as the enduring staff while paying extra time gives the open entryway for the staff to acquire.

\subsection{High Representative Turnover}

High specialist turnover was referenced as an issue. According to "different delegates gave up considering the way that they were offered better remuneration by various lodgings. They labored for a couple of months, and a while later left". To address this issue, the chairman drove a post-work study to find why they gave up and to put forth an attempt not to leave.

\subsection{Terrible Showing}

Horrendous indicating was referenced as an issue by eight individuals. Scenes that reflect horrendous demonstrating were giving guests an improper key, cash inadequacies, and moderate assistance. It communicated: "There are staff that are not 
viable yet rather not a lot of. Sometimes these laborers give a wrong key to the guest. I gather they lose focus". It in like manner uncovered cash need issue. As demonstrated by some new staff people are moderate and inefficient regardless of the way that they by and large improved in the wake of getting ready.

Directors comprehended the issue of horrible appearing by giving consistent getting ready. It communicated: "We have to send them for getting ready. Retrain them with the objective that they could pass on better help of the guests." As per agents who have passed probation period are given a counsel letter if their work standard is underneath a commendable level. After the third notification letter, the agent can be finished. Answers for issues of cash lacks changed beginning with one affiliation then onto the following It communicated: "In this housing delegates are required to cover the lack by paying in genuine cash or by pay decline. A couple of motels anticipate that delegate should give a 'show cause' letter."

\subsection{Low-Gifted Workers}

Low-capable laborers had poor social capacities, English ability, and basic reasoning and PC aptitudes. Poor social capacities were referenced by three individuals and concerned phone conversations, poor English language ability and confusion customers. According to a couple of laborers misconceived their commitments and fail to cling to bearings. It referenced a weakness to pass on in English was an issue with some staff. It referenced a weakness to hold fast to standard action frameworks in getting the phone: "Some staff doesn't have the foggiest thought how to get the phone suitably. In hotels standard strategy to get the phone Aversion at home where essentially make legitimate colleague'. Positioning staff people who have worked here for a long time It is difficult to change their procedure for getting the phone anyway are so far difficult".

\subsection{Horrendous Character}

An upsetting character was represented as an issue by six individuals and was related to inconsiderateness, antagonistic vibe and horrible mood. It nitty gritty having these sorts of issues with new young delegates They are extraordinarily boisterous, and they envision that people ought to recognize them the way wherein they are, especially when they live in the district where people are used to it. It is important to accept to upset the rowdiness and improve their correspondence capacity. To them it is just being cool since they are young. Regardless, at the front office can't do that?

\subsection{Absence of Duty}

Nonappearance of duty was the most routinely referenced lack on help. Non-appearance, delay, long late morning break, helpful leave and emergency leave were a part of the shortages on help that were related to a nonattendance of obligation. Non-appearance and deferral were most as regularly as conceivable referenced. It was the principle executive who referenced long early afternoon breaks and considered it to be a minor issue that could be clarified by verbally admonishing the staff. According to visit truancy is a troublesome issue to the front work zone office in light of the fact that there are just a few them to run the action. The issue is most observably awful in case it happens on a clamoring day when the hotel occupant is high. It communicated: "considering the way that one staff was absent on a clamoring day it required some speculation to enroll the guests. That day various protests since they expected to keep it together for so long".

\subsection{Excessive Socialization}

Superfluous socialization was represented as an issue by three individuals. According to her front work territory delegates were ceaselessly talking and snitching with each other instead of accomplishing their work. It communicated that her laborers needed to confer their mistake towards the officials to their accomplices rather than using the right channel for a 
complaint. She explained that once in a while a boss may surprisingly show prejudice towards a person from staff and this causes dissatisfaction among other staff who snitch about the issue. It referenced that in his housing, laborers mistakenly accepted that no move was made about an agent who was late and they were pained about it. In any case, move was made anyway due to the security of the issue others were not instructed. It communicated: "Staff talk without confirming. The grapevine has made a piercing working air". It endeavored to address this issue by having step by step briefings and without fail social events. In this social event, staff people were enabled to talk and there was "two-way correspondence". This was a way to deal with avoid 'the grapevine' and superfluous socialization.

\subsection{Lewd behavior}

The issue of wrong conduct was referenced by only a solitary part. As demonstrated by salacious conduct now and again happens anyway it is a noteworthy issue when it happens especially for female specialists. It communicated: "For wrong conduct, the front office executive will make an energetic move. She will investigate if the report is substantial or it is just a joke. If the report is substantial, the manager will rebuke the harasser by making disciplinary move and rethink his presentation at work."

\section{CONCLUSIONS}

There has been a fast improvement of the movement business in India since 1970. To improve Indian, the movement business positive picture, the workplaces and organizations gave by the movement business related heads should satisfy customers' wants. Regardless, meeting customers' longing is continually a test especially in the housing industry due to the business' work heightening. This assessment of shortages on help in lodgings of various sizes and zone using abstract examination has incited the exposure of various challenges in the Indian motel industry and plans to address them. It has included issues that are now and again referenced in the composition and has suggested answers for current shortages on help looked by motel boss. The most significant components in visitor fulfillment driving to rehash clients are normalized items, spurred what's more, and prepared staff \& quality administration. A general view of the examination shows that the greater part of the visitors is fulfilled with the general administrations of the Front office.

\section{REFERENCES}

1. Heyes, "Hotel front office management," in Hotel Accommodation Management, 2017.

2. K. Artto, I. Kulvik, J. Poskela, and V. Turkulainen, "The integrative role of the project management office in the front end of innovation,” Int. J. Proj. Manag., 2011.

3. T. Giesbrecht, B. Schenk, and G. Schwabe, "Empowering front office employees with counseling affordances," Transform. Gov. People, Process Policy, 2015.

4. T. Giesbrecht, H. J. Scholl, and G. Schwabe, "Smart advisors in the front office: Designing employee-empowering and citizencentric services," Gov. Inf. Q., 2016.

5. T. Kearney, G. Walsh, W. Barnett, T. Gong, M. Schwabe, and K. Ifie, "Emotional intelligence in front-line/back-office employee relationships," J. Serv. Mark., 2017.

6. S. Aguirre and A. Rodriguez, "Automation of a business process using robotic process automation (RPA): A case study," in Communications in Computer and Information Science, 2017.

7. U. Karmarkar, "The industrialization of services," in Managing Consumer Services: Factory or Theater?, 2014. 
8. S. Birken et al., "Office-based randomized controlled trial to reduce screen time in preschool children," Pediatrics, 2012.

9. L. F. Luna-Reyes, J. R. Gil-Garcia, and J. A. Celorio Mansi, "Citizen-centric approaches to e-government and the back-office transformation," in ACM International Conference Proceeding Series, 2011.

10. W. A. Calo et al., "Experiences of Latinos with limited English proficiency with patient registration systems and their interactions with clinic front office staff: An exploratory study to inform community-based translational research in North Carolina," BMC Health Serv. Res., 2015. 

